\title{
The language factor in the search for national cohesion and integration in Kenya
}

\section{Stephen Omondi Owino}

\section{(2) OpenEdition \\ 1 Journals}

\section{Electronic version}

URL: https://journals.openedition.org/eastafrica/406

DOI: $10.4000 /$ eastafrica.406

ISSN: 2790-1076

\section{Publisher}

IFRA - Institut Français de Recherche en Afrique

\section{Printed version}

Date of publication: 1 September 2013

Number of pages: 57-69

ISSN: 2071-7245

\section{Electronic reference}

Stephen Omondi Owino, "The language factor in the search for national cohesion and integration in Kenya", Les Cahiers d'Afrique de l'Est / The East African Review [Online], 47 | 2013, Online since 07 May 2019, connection on 09 December 2021. URL: http://journals.openedition.org/eastafrica/406 ; DOI: https://doi.org/10.4000/eastafrica.406 


\title{
The language factor in the search for national cohesion and integration in Kenya
}

\author{
Stephen Omondi Owino
}

\section{Introduction}

Kenya has institutionalized the management of diversity by the creation of the National Cohesion and Integration Act, 2008 and eventually a commission to implement it. This Act isolates and focuses on only two principal categories of diversity, namely race and ethnicity. This choice is most probably due to the fact that they are the differentiating categories underlying some of the violent conflicts in recent history of pre-independence and post-independence Kenya. There is a linguistic dimension to these categories. The racial category carries along with it the linguistic differentiation of foreign languages versus the native languages while the ethnic category engenders differentiation into national and communal languages. If we bear in mind that language is tied to the construction of identities and relations of difference, then it becomes problematic as to what extent language can influence conflicts due to diversity or contribute to synergetic diversity. Entrenching the Act on cohesion and integration in Kenya must therefore be accompanied by discourses which thematise diversity. The paper is an attempt to explore the linguistic dimension that may make a positive contribution to the elaboration of a discourse of diversity and cohesion in Kenya. The paper is informed by the theory of social systemism. It attempts to incorporate language as one of the structuring relations between the components of a social system. Moreover it is assumed in the paper as axiomatic that language is a social asset and resource that should be employed to solve social problems, in which regard the paper specifically attempts to review the potential for negative construction of identities of the current language policy in Kenya.

\section{Systemic Conception of Society}

The nature of human groups can result in many views regarding their composition. Our conception of diversity results from such views. Diversity can be conflictual or co-operative. Conceptions of diversity that result in mutual understanding and co-operation are more desirable than those that encourage competition and conflict. The paper proposes the view that the linguistic component is critical in promoting co-operative diversity in society. In the paper we adopt the systemic view which might appear to be at odds with the theme of diversity. But before we elaborate on this view we may have to consider two competing alternative approaches to the nature of society, namely individualism and holism. 
Individualism holds that a society is essentially a collection of individuals. The history and properties of a society are a result of the union of the histories and properties of the individual members. This view has a concomitant ontology which denies existence of social objects and emergent social properties. It equates social change with the sum of changes in the individual members of the society and interaction between two societies is equal to interaction between their individual members. In a nutshell individualism holds that the state of a society is a function of the state of its individual components. The corresponding methodology of individualism is that:

a) The study of society should proceed by the study of the individual

b) Social facts should be explained in terms of individual intentions and action

Sociological hypotheses and theories should be tested only by observing the behaviour of individuals

The outgrowth of this methodology is the cult of statistics that compute aggregate figures, averages and their deviations out of individual data. While admitting the validity of this methodology for resultant properties such as in demography and income, it is noticeable that it fails when we are confronted with emergent properties such as social structure and political stability. This reveals that a comprehensive understanding of the individual can be achieved only if we also factor in institutional framework and historico-cultural situations in our analysis.

Holism views society as a totality which transcends its membership and having emergent properties which are distinct from those of its members and their interactions. The society as such is more than the sum of its members. Its ontological presupposition is that the state of an individual is a function of the state of the society in which it is embedded. When radical and consistent, totalitarianism is the derivative of holism. Correspondingly, the methodology of holism is that:

a) The study of society equals the study of its emergent properties

b) Social facts should be explained in terms of supraindividual units such as the state or in terms of supraindividual forces such as class consciousness

c) The hypotheses and theories of social science are beyond empirical testing (speculative holism) or must be checked against global data (analytic holism)

Systemism is a synthetic view proposed by Mario Bunge $(1983,2003)$ that integrates the insights of individualism and holism while eschewing their defects. It views a society as a concrete system of interconnected individuals with both resultant and emergent properties. Its ontological thesis is that the state of a society is a function of the properties of its individual members and vice-versa. Its method is a unique synthesis of rationalism and empiricism proposed whose core theses are: 
a) That the study of society should include the study of socially relevant features of the individual as well as the emergent properties and changes of entire social groups

b) Social facts should be explained in terms of interaction of both individual and social groups

c) The hypotheses and theories of social science should be tested interdisciplinarily

I submit in this paper that language is a social fact that warrants such a systemic study and that multilingualism is a socially relevant linguistic feature which is both resultant and emergent in a society. As a resultant property it may be used to describe individual multilingualism which refers to the collection of individuals that can use more than one language to express themselves and as an emergent property it might describe the social multilingualism which refers to a society with many distinct linguistic groups.

\section{The Problem}

Language is tied to the construction of identities and relations of difference. In a multilingual setting this dual role of language can create conflicts between constructed identities and representations of differences. It is therefore problematic and imperative to establish the extent to which language can fuel conflicts due to diversity or contribute to synergetic diversity. Entrenching the recently enacted Act, 2008 on cohesion and integration in Kenya must therefore be accompanied by discourses which thematise diversity if it is hoped to achieve its functions and objectives. This paper seeks to establish the hidden forms of divisive diversity that the National Cohesion and Integration Commission may factor in their efforts to operationalize the act.

\section{Hypothesis}

One widely held hypothesis by sociolinguists is that linguistically homogenous polities are usually more developed, educationally more advanced, politically more modernized and ideologically-politically more tranquil and stable. Alternatively phrased it states that a country that is linguistically highly heterogeneous is always underdeveloped and a country that is developed always has considerable linguistic uniformity (Fishman 1968, Pool 1972). This hypothesis suggests that monolingualism is a necessary condition for development.

But in this paper I propose a weakened formulation of the same hypothesis to suggest that linguistic diversity is a sufficient condition for social instability; if not well managed, it can lead to social conflict and disintegration. This means that it is not a precondition for underdevelopment but rather a conducive one if recklessly manipulated 


\section{Sociolinguistic Character and Language Policy in Kenya}

According to Whiteley (1971), Kenya has approximately 40 languages distributed as follows: $66 \%$ Bantu, 31\% Nilotic and the rest comprising Cushitic, non-indigenous European and Asian. This establishes Kenya as a multilingual country like many African states. In order to classify the various linguistic characteristics of the African states Nida and Wonderley (1971: 57-74) identify two typologies of sociolinguistic character of African states. The first is a 3language structure wherein an in-group language is used for intra-ethnic communication at a sub-national level; an out-group language is used for interethnic communication involving non-specialized information and; lastly, a language used for wider communication both nationally and internationally and expression on subjects that require specialized information. Secondly, there is a 2-structure language, which consists of an in-group language and a second language that serves both the inter-ethnic and the specialized functions. Kenya has a three-language structure.

Kenya lacks a written language policy, except for parliament and education. Nevertheless, this can be discerned from the overt linguistic practices in the country. Of her approximately 42 languages some are considered dominant on the basis of the population of the native speakers. The dominant ones are Kikuyu, Dholuo, Luluhya, Kikamba, Kalenjin, Ekigussi and Kimeru. The national language is Kiswahili spoken by about $65 \%$ of the population as a second language and as a first language by the Swahili at the coast. English and Kiswahili are the official languages.

In education, the indigenous languages are taught and used as languages of instruction in the first three years of primary school in the rural schools while in the urban centres, Kiswahili substitutes for indigenous languages during this period. From the fourth year, English becomes the language of instruction in all schools up to the university level. While English has become the language of instruction, together with Kiswahili they remain compulsory languages studied and examined from primary school to the end of secondary school. At the secondary school level, foreign languages are included as optional subjects examined for those who opt to study them to the fourth form. These are Spanish, German and French with a majority who opt for this category preferring French. No indigenous language is studied after the third year in primary school.

In the media, most daily newspapers are in English with only one Kiswahili daily. Television broadcasts are in English and Kiswahili. It is in radio that there are besides English and Kiswahili stations, there are many other stations that broadcast in indigenous languages and one that does in French, Radio France Internationale. 


\section{Managing Diversity in Kenya}

Diversity can be either co-operative or competitive. Competition can result in or from conflict of interests and tensions which might lead to social instability. Any attempt to mitigate such negative competition of diversity is part of social engineering or management. Kenya has made the attempt to do this by instituting the National Cohesion and Integration Act, 2008. The act makes discrimination based on ethnic or racial grounds a criminal offence. The articles with relevance to language are two:

1. Hate speech which has become a criminal offence and it includes:

a. Using threatening, abusive and insulting words or behaviour or display of any written material

b. Publishing or distributing such material

c. Presenting or directing the performance of play with such content

d. Distributing, showing a play or recording of visual images with such content

e. Producing or directing a programme which is threatening, abusive or insulting that is intended to stir up ethnic hatred

f. Offenders of hate speech will face a fine not exceeding 1 million Kshs or 3 years in prison or both

2. Promotion of the respect for religious, cultural and linguistic diversity as one of the objectives and functions of the National Cohesion and Integration Commission.

\section{Language-Based Problems and Language Problems in Africa}

Systemism commits us to recognize that human groups are systemic with definite but changing components and structures, embedded in definite but changing natural and social environments. They have four critical dimensions namely; biological (kinship), economic, political and cultural (i.e. the set of cognitive, moral and aesthetic activities and relations). The system can be dysfunctional with respect to any one or more or all of these dimensions. Webb and Kembo-Sure (2000) have identified four language-based problems related to some of these social dimensions:

i. Restricted access to knowledge and skills:

While there may be many reasons for the restriction to access to knowledge and skills, language does contribute in a significant way to block or slow the acquisition of cognitive skill such as ability to grasp the central issue of a text, to follow its main line of argument; the ability to unite and systematize information coherently; the ability to discover and formulate generalizations; the ability to grasp the core concepts and their articulation in theories which compromises the ability to recognize underlying relationships between facts and 
events. These cognitive skills can only be developed and optimally exercised in a language one is very competent in. In Kenya, majority of people who have completed high school are generally functionally illiterate in English. The English they know is not sufficient for the articulation of high level thinking and effective public life. It limits their access to information, knowledge and skills imparted by the language. Thus, the continued use of English is contributing to undereducation in Kenya indicated by poverty of conceptual stock, difficulty in generalizing, incapacity to entertain hypotheses, incoherence in reasoning and the general lack of interest in abstraction among students.

ii. Low productivity and ineffective performance in the workplace:

Communication in the working place involves the use of certain languages. Access to employment opportunities is seriously compromised due to incompetence in the language employed in the economic activities of the society. The specifics of communication might include aspects such as training and skill development; work communication; contracts; public notification and workrelated documentation such as terms and conditions of employment. Poor language skills can therefore imply exclusion from the economic life of the society

iii. Inadequate political participation:

Political participation is fundamental for the operationalisation of democracy. In contemporary times political development is measured on the standard of democratic evolution of the state. Kenya scores poorly on this because there is little demonstration of any meaningful citizen participation in political processes. The dominant mode of political participation which is casting of votes is extremely under the influence of manipulation.

There are two linguistic dimensions to this phenomenon. The first is the predominant use of English and Kiswahili to carry out political debate and services such as the proceedings in law courts and health services. This lowers the level of debate in the public sphere and access to public services due to incompetence in the language in use. The second is the propensity to use language to carry out divisionism, discrimination, exploitation and political manipulation. For instance, in Kenya, the administrative districts which have since the promulgation of the new constitution been renamed counties are generally based on linguistic differences.

iv. Linguistic and cultural alienation:

Many factors as diverse as the colonial legacy, educational policy, power relations and socio-economic roles have created among Kenyans a generalized preference for English and Kiswahili to other local languages. This pushes towards language shift, with the consequence of impoverishment of local languages. Ultimately, this process would lead to loss of local languages, identities and diversity. This more importantly so with the recognition that language is not only a means of expression but is also a depository of cultural knowledge and experience. In this respect, the death of a language is analogical to the burning of 
a library because it implies obliteration of an entire world view and collective wisdom of a people.

\section{v. Problem of Conflict and Nation-building:}

The preamble of the National Cohesion and Integration Act in Kenya makes discrimination on the basis of ethnic or racial grounds a criminal offence. It equally bars the comparison of persons of different ethnic groups and makes it illegal to harass another person on the basis of race or ethnicity. This is an indication that tensions motivated by race and ethnicity exist in the Kenyan society. Such social divisions carry a potential for conflict which can be fanned by language employed as a socio-cultural identity marker. Language in itself is neutral in these matters but its manipulation as a socio-political tool can lead to social conflicts. In Kenya this is evidenced by the tendency to create political movements and parties with membership having a specific ethno-linguistic character. This has occasioned in every election year since the rise of multiparty politics, ethnic violence which have concomitant politico-linguistic variations.

With regards to nation-building language factor has the potential to create tension between nationism and nationalism. The nationalist project came to the foreground after independence with political leaders attempting to construct national unities. This was the motivation for preferring the ex-colonial languages on the argument that they are not anybody's primary language so they portend less risk for stirring up conflict. The indigenous languages were viewed as potentially divisive hence a threat to national integrity. But in the background there are still the ideals of liberation struggles which upheld right to selfdetermination and preservation of cultural diversity. These ideals inspired liberation nationalist movements but still continue to pose the threat to inspire language-based separatist movements such as the pre-dominantly Igbo-speaking Biafra movement in Nigeria which wanted to secede from the country.

But besides language-based problems, Webb and Kembo-Sure indicate the existence of language problems. The former are problems in the domain of education, politics, economy and social life with a language component. Language plays a critical role in their occurrence such that their solution must involve a linguistic facet. On the other hand, language problems are directly linked to language itself. Some of the language problems they identify that relate to Africa are:

a) Insufficient adaptation of African Languages:

This describes the perception that African languages are ill-adapted as "instruments of learning, economic activity, social mobility, or for any other serious public business" (Webb \& Kembo-Sure op.cit.: 15). They are considered poor in scientific and technological terminology therefore inadequate in a modern world that is built on a scientific and technological culture. This is attributable to many factors among which are the historical experiences of subjugation which made everything African to be a subject of scorn. Besides, the 
economic backwardness of the continent has created asymmetric relations between the local languages and those of the economically dominant ones. But while admitting the actual inadequacy of the local languages for such specialized functions we need to remember that in principle all languages have the same expressive power. What is needed is to subject the local languages to challenge so as to develop their functional utility and social status.

b) Politicization of Languages:

Politicization of language can be described as a process in which languages are infused with political meanings thereby becoming associated with or excluded from a political programme. It is evident that language is a site for the construction of identities and representations of the others. These constructions feed ethnic chauvinisms and negative stereotypes of the other language communities. In these constructions for instance some communities are represented as inferior, backward, greedy, friendly or hostile. The stigmatizations often breed attitudes towards others that are often exploited by manipulative politicians to stir ethno-linguistic intolerance. In Kenya for example people frown upon speaking of vernaculars in public places for fear of being branded tribalists.

c) The problem of standardization:

The adoption of certain varieties of a language as the standard variety is common in any society. For example, in Kenya, British English commonly referred to as the "Queen's English" or "BBC English" and the Kiunguja variety of Kiswahili spoken in Zanzibar and Pemba are the standard varieties of English and Kiswahili respectively. Standard varieties naturally become politicized since they are generally incorporated into the general socio-economic policies of the country. But standardization raises other issues that might be of serious consequences. Career opportunities can be determined by the mastery of the standard variety thus forming a tacit basis for discrimination. The perception of the standard variety as having a higher social status can also lead to the alienation of nonstandard speakers whose variety might have a diglossic disadvantage thereby perceived as less serious or uncultured people in public debates. Besides, those whose variety is taken as the standard language may be facilitated to progress economically and socially thereby creating imbalance of power relations between communities.

There are two approaches to addressing language as a problem. The first is the standardization model. This model addresses specifically the language problems directly as such. It proceeds by way of corpus planning and status planning. Corpus planning focuses on the internal efficiency of language through the standardization of its vocabulary and syntax. Status planning focuses on developing the functional range of language through the expansion of its use and social prestige. Kenya lacks a standardization body but it does endorse the standard British English and the recommendations of the Kiswahili Research Institute affiliated to the University of Dar-es-Salaam, Tanzania. The local languages are virtually left out in this model. 
The second approach is the social-management model which regards language as a social resource and asset that should be harnessed towards the solution of social problems. It is most appropriate in addressing the languagebased problems. The focus in this model is on issues such as, language and ethnicity; inter-group relations; social stereotypes; language attitudes, among others. It therefore draws attention to the complex social, cultural, economic and political issues that emerge in a multilingual context thereby side-stepping the purely structural questions of language.

\section{Systemic Approach to Diversity and Nation-Building}

A discourse on systems in a context where diversity is thematic raises suspicion of a contradiction. But the systemic approach does accommodate diversity in its construction of society. A system is defined as a structured set of objects embedded in an environment. The objects constitute the components of the system. There are two sets of relations that give structure to the system. The relations between the components of the system give it its internal structure while the set of the relations with its environment gives it its external structure. It is possible to have a system whose components are systems in which case the former becomes a super-system to the latter systems which become its subsystems. Systems can therefore range from physical to social. A polity is an instance of a social system analyzable in terms of the above parameters of components; structure and environment. Language is one of the structuring elements of a social system and moreover it is instrumental also in the realizations of other relations such as economic, cultural and aesthetic.

A system can therefore be deemed stable and cohesive in function of the stability of its uniting relations. The components of the system might be enormously diverse but that in itself does not warrant the emergent instability of the system. It is rather the cohesive potential of its structuring relations that we need in order to determine the systems cohesion and stability.

\section{Language and National Cohesion}

We start from a basic sociological law which states that participation enhances social cohesion which implies that in order to enhance social cohesion promote participation and promoting social disintegration discourages participation. As we have seen in the previous section on the language-based problems and language problems it is clear that language is directly correlated to social participation. Proficiency in a language is not enough to enhance participation but equally important is favourable social status accorded the given language. In the Kenyan case it is observed that the majority of Kenyans lack proficiency in the languages with higher social status and the contrary also holds in that, the languages they have proficiency in lack high social status. This simple phenomenon hinders majority from effective participation in public domains. 
Tied to that is a much more intricate issue of access to opportunities which is tied to linguistic competence in the languages with wide social functions. In Kenya these are English and Kiswahili whose standardized forms are predominantly imparted in school. The quality of education indicated by variables such as libraries and qualified competent teachers is a determinant of the level of linguistic proficiency a learner acquires from the school. Distribution of resources biased by ethnic considerations in post-independent Kenya has given rise to the concentration of better schools in some regions than others. This has the impact of developing unbalanced power relations between communities and perpetuating reproductions of social inequalities.

The National Cohesion and Integration Commission must therefore expand the scope of its activities to include the much hidden and subtle factors that are dependent on language if they are to succeed in realizing national cohesion. The dominant concern with "hate speech" and its attendant controversy on infringement of freedom of speech and the right to privacy might cloud the subtle modes of differentiation that threaten national cohesion. The realization that the bulk of these modes have a language component impels the commission to spearhead the formulation of much broader national language policy. The government should institutionalize a language planning agency within the framework of NCIC.

\section{Language Policy as Integral to Sociotechnology}

The challenge for the agency would be how to harness multilingualism as a cultural heritage and a resource for Kenya's benefit. This paper contends that a sound language policy is both fundamental and capital in meeting this challenge.

Multilingualism which is a brute fact in Africa can be dangerous as various cases in Africa and Eastern Europe demonstrate when exploited and manipulated by selfish interests. However, when viewed and cultivated as a resource it can be of great use to the nation, community and the individual for instance, in enhancing the resolution of the nationist-nationalist conflicts, the dynamism of the society and the interactive capacity of individuals.

It is important to note that language-based problems transcend language problems and play a central role in areas of education, economy, politics etc. Their solution therefore lies in tackling language problems and formulating extensive and rigorous language policy. Falloux and Talbot (1992: 119) note that for any success of any programme to be realized, people must participate in the design, execution and monitoring of the projects and programmes.

We observe that in most development interventions in Africa, this participation occurs at the micro levels of village and urban communities. But to be effective, these interventions must lead to durable, self-sustaining development and not merely temporary growth. This in its turn requires strengthening of local capacities, supporting indigenous entrepreneurship and unlocking the propensity for self-organization within local culture. According to 
Uphoff (1991: 84), such participation is specifically necessary at the micro level for effective utilization and management of the system after the state and her external partners, engineers, economists and environmentalists are finished with the technical planning. For such active participation to be realized, a good proficiency in the language employed is a necessary pre-condition. That is when the intended beneficiaries of the programmes participate effectively in the discourse pertaining to their interests.

But the major paradox, which is a language problem, is whether the languages popularly in use at these micro levels have the technical and scientific terminology that is required to understand the complexities of today's world and the expert language of development interventions. This fear is easily allayed when we realize that any human language is capable of coping with and express its immediate realities and to expand its lexical repertoire to cope with and express any novel reality by means of various word-formation processes e.g. coinage, borrowing, blending, etc. Obanya clearly points this out by saying that:

"A language grows by being used. Using a language for education, for business, for socio-cultural activities, for administration, etc exposes it to challenges. Like human beings, languages also adapt, invent, and innovate to meet new challenges" (1999: 484).

The Kenyan government has little option but to pursue policies extensive and rigorous enough to accommodate multilingualism, aid the development of native languages thereby enhancing public participation at both micro and macro levels of the society.

\section{Conclusion}

In conclusion I give what I consider to be the general guiding principles for formulating a policy on language and communication in Kenya. The need for a language and communication policy cannot be overstated. Mazrui and Mazrui have noted that "language planning is usually part of wider social engineering and is used in order to achieve other goals such as political participation and national integration" (1998: 85). Okombo also observed that "the whole idea of language planning as a policy matter belongs not to the restricted domain of language but to the wider field of public policy dealing with language only as a factor on national development and government concerns".

In the light of what I have discussed in the preceding sections, I therefore propose some principles consistent with our systemic approach that aim at integrating the objectives of nation-building and the multilingual reality of Kenya.

The guiding principles for such integration can be enunciated as follows: 
a) Maintain the use of English as the official international language of wider communication. Besides, the learning and acquisition of other languages of wider communication e.g. French, German, Spanish etc. be encouraged. In the scheme of systemic approach, these languages would establish the external structural relations to enable Kenya to interact through some of its components with the international environment in which it is embedded. This allows the polity to remain as an open system able to access the outside world and also to exchange information, specialized knowledge and discourse with the outside world.

b) Encourage and maintain the use of Kiswahili as our national language of wider communication especially for purposes of facilitating national and interethnic interaction. Kembo-Sure and Ogechi (2006) have also proposed the adoption of Kiswahili as a medium of instruction and examination for subjects such as history, government, social studies and geography throughout primary and secondary school education. In terms of social systemism it would enhance the stability of the polity by strengthening its internal structure and cohesion.

c) Promote the use of indigenous languages in order to remedy their diminished use and status. The indigenous languages do provide the structural relations within the communities which are embedded in the polity as the latter's components or sub-systems. In this regard, Kiswahili would provide the external relation between a community and the rest of the polity acting as the environment. Some ways of enhancing the use of indigenous languages include the following:

- Maintain their use as the medium of instruction at the primary school level to enhance cognitive development and acquisition of skills. This is particularly important for those who do not proceed with school beyond primary level whose interactive range consequently get restricted mainly to the local community where they require mostly the intra-community language.

- At the local government level

- In the local law courts

- Translation into the indigenous languages of vital documents e.g. the constitution, law reports, official government communiqués etc.

- Broadcasts through the mass media e.g. radio, telecasts, newspapers to the regions of programmes that address matters of interest to the people in their indigenous languages. For example, programmes on nutrition, Aids, Pastoral health, Arts and culture, entrepreneurship, family planning, marketing etc. Such a communication strategy would tailor programmes to the needs of the people and help in their implementation. It would also aid the indigenous languages in appropriating the technical information so transmitted. 


\section{Bibliography}

Bunge M. 2003, Emergence and Convergence, Toronto: Toronto University Press Inc. -1983, Treatise on Basic Pbilosophy, Vol. 6, Dordrecht/Boston: D. Reidel Publishing Company.

Falloux, F. \& Talbot L. 1992, "Political Involvement and Popular Participation" in F. Falloux \& L. Talbot, (eds.), Crisis and Opportunity: Environment and Development in Africa, London: Earthscan Ltd.

Fishman \& Pool, 1968 \& 1972, quoted by Wolff H. Ekkehard, “The Language Factor in Discourse on Development and Education in Africa" in Kembo-Sure et al (eds.), Language Planning for Development in Africa, Eldoret: Moi University Press.

Kembo-S. \& Ogechi N. 2006, "Language Planning and Reform: An alternative language policy for Kenya", in Kembo-Sure et al (eds), Language Planning for Development in Africa, Eldorent: Moi University Press.

Mazrui, A. \& Mazrui A. 1998, The Power of Babel: Language and Governance in the African Experience, Oxford: James Currey.

Nida \& Wonderley 1971, "Communication Roles of Languages in Multilingual Societies", in W.H. Whiteley, Language Use and Social Change: Problems of Multilingualism with Special Reference to Eastern Africa, Nairobi: Oxford University Press, pp. 57-74.

Obanya P. 1999, The Dilemma of Education in Africa. Dakar: Unesco Regional Office.

Okoth O. 2001, Language Policy: The Forgotten Parameter in African Development and Governance Strategies, Inaugural Lecture to the University of Nairobi.

Uphof N. 1991, "Fitting projects to People" in Cernea, M.M. (ed.), Putting People First: Sociological Variables in Rural Development, 2nd Ed., New York: Oxford University Press.

Webb V. \& Kembo S. 2000, "Language as a Problem in Africa", in Vic Webb and Kembo-Sure, (eds.), African voices: An Introduction to the Languages and Linguistics of Africa, Cape Town: Oxford University Press.

Whiteley W.H. 1971 (ed.), Language Use and Social Change: Problems of Multilingualism with Special Reference to Eastern Africa, Nairobi: Oxford University Press. 